\title{
JUSTICIA Y TÉCNICA: UN PUNTO DE VISTA PRAGMATISTA
}

\author{
Jaime Fisher ${ }^{1}$
}

\section{Resumen}

El ensayo defiende una concepción de la política como técnica. En consecuencia se propone cierto concepto de justicia que permite caracterizarla como el objetivo fundamental del sistema técnico-Estado, o sistema político. Con base en el naturalismo pragmatista e instrumentalista (experimentalismo) de John Dewey, de forma paralela se entiende a la libertad del ciudadano como el fin de la política aparejado al objetivo técnico de la justicia. El sistema político es concebido, pues, como el sistema técnico básico, y el Derecho como su instrumento central. Por último, se intenta ubicar las características fundamentales de una filosofía política naturalista mediante su contraste con las posiciones de Rawls y Nozick en torno al tema de la justicia.

Palabras clave: técnica, justicia, libertad, estado, pragmatismo, instrumentalismo.

\section{INTRODUCCIÓN}

Este ensayo es producto parcial de un proyecto más amplio de investigación relacionado con el naturalismo filosófico y con el pragmatismo. Constituye un primer intento por poner a trabajar el experimentalismo o instrumentalismo deweyano en la filosofía política y en sus temas fundamentales, a saber, la justicia y la libertad. Se parte de la creencia implícita en la eficiencia de las ideas centrales de John Dewey para, desde un sentido común alejado de todo planteamiento metafísico, pensar hoy los problemas sociales, culturales y políticos que, en buena medida, están asociados al desenvolvimiento de la ciencia y la tecnología, y que son mediadas por la economía. En la primera sección, pasando breve revista a la tradición filosófica al respecto, se presentan dos conceptos pragmatistas de justicia y libertad vinculados con las nociones de técnica y de sistema técnico. La segunda parte intenta una naturalización de la noción de justicia, vinculada a la de libertad, en las acciones intencionales humanas. Para ello se discuten los conceptos de igualdad, equidad e imparcialidad en tanto relacionados con los de justicia y libertad. En la tercera sección se reseñan los argumentos que, dentro de la tradición liberal, pueden encontrarse en autores muy conocidos como John Rawls y Robert Nozick, y se les coteja con los que podemos hallar en la filosofía política de John Dewey. Se apuntan y defienden las ventajas que tendría

\footnotetext{
${ }^{1}$ Doctorado en filosofía de la ciencia por la Universidad Nacional Autónoma de México. Investigador de tiempo completo en el Instituto de Filosofía de la Universidad Veracruzana. E-mail: jaime.fisher@gmail.com 


\section{Quaestio Iuris}

este último autor respecto a los dos anteriores dentro de la misma tradición liberal. Por último, se concluye que la teoría pragmatista de la democracia sustantiva desarrollada por Dewey resulta de actualidad y pertinencia en torno a las necesidades de control racional del Estado, entendido como el sistema técnico fundamental.

\section{JUSTICIA Y LIBERTAD}

Quizá no haya mejor manera de identificar un tipo particular de filosofía política que analizando la forma en que enfrenta el problema básico en el campo, a saber, el de la justicia. Éste es el asunto público nodal del Estado qua sistema técnico y, como dice Perelman (1964, p. 15), "entre todas las nociones prestigiadas, la justicia parece una de las más eminentes y la más irremediablemente confusa." En este mismo tenor Kelsen (1991, p. 1) afirma que "sobre ninguna otra pregunta han meditado más profundamente los espíritus más ilustres -desde Platón a Kant-. Y sin embargo, ahora como entonces, carece de respuesta. Quizá sea porque es una de esas preguntas para las cuales vale el resignado saber que no se puede encontrar jamás una respuesta definitiva sino tan sólo preguntar mejor." Por supuesto, no se pretende aquí acuñar un concepto de justicia que resuelva, de una vez por todas, la añeja discusión al respecto, sino preguntar mejor, donde preguntar mejor es hacerlo -según propongo- desde el pragmatismo experimentalista. Sin embargo, no hay en los autores clásicos de esta escuela (Peirce, James, Dewey, Lewis, Mead) un desarrollo pleno del tema, y las referencias que se hallan entre ellos son escasas y dispersas, situación que requiere y permite ensayar ese enfoque filosófico sobre el asunto.

Puestos a ello -y recordando que el pragmatismo ubica a la acción humana en el centro de la reflexión filosófica-, podemos concebir la justicia en tres niveles o dimensiones:

1. como un valor, es decir, como un acto humano de valoración sobre determinado estado de cosas, existente o posible de traer a la existencia mediante la acción práctica (Dewey, 2012);

2. como el enunciado de una regla o conjunto de reglas aplicables para alcanzar ese estado de cosas valorado; y

3. como acto o ejecución en seguimiento de esas reglas y orientado a la consecución de lo valorado como justo ${ }^{2}$.

La justicia es entonces un asunto práctico, un asunto que tiene que ver con la consecución técnica de ciertos estados de cosas. Como toda idea pragmatista, la justicia es observable si funciona y se integra en una determinada estructura de acciones intencionales humanas. La idea complementaria es la de adscribir al Estado -un sistema

\footnotetext{
2 Sigo en esto a Perelman (1964 ). La visión instrumentalista o experimentalista diluye el dualismo hecho-valor en la acción intencional misma: toda acción intencional implica una valoración sobre los hechos en dos sentidos: a) elige los hechos que vale la pena transformar, $y b$ ) valora el sentido en que han de ser transformados.
} 


\section{Quaestio Iuris}

técnico ${ }^{3}$ la concepción misma del valor justicia, la elaboración de la regla práctica para enunciarla y alcanzarla, y la ejecución del acto ('correctivo' o 'distributivo') que produzca ese estado de cosas. ${ }^{4}$

Estas tres dimensiones discernibles en el concepto tienen origen empírico. La noción misma de justicia como un estado de cosas posible, el asunto práctico de una regla que enuncie o prescriba cómo producirla, y el acto efectivo que la realice, pueden tener lugar sólo puestos ante su contrario, esto es, ante la injusticia. Las condiciones de posibilidad de la justicia están dadas por su inexistencia, y por la percepción de la necesidad de traerla a la existencia. Nuestra primera experiencia al respecto es siempre y por necesidad una irritación que, para ser considerada como una injusticia, debe hallarse -bajo alguna descripción razonable- entre los resultados intencionales o no intencionales de las acciones de un ser humano. La injusticia es definida como una violencia antropogénica. Esa irritación y violencia constituyen una injusticia si, y sólo si, al menos un ser humano las producen -en el medio ambiente físico o simbólico-, y al menos otro las padece sin justificación racional. Por ello hay que considerar primero esas circunstancias de posibilidad de la injusticia, es decir ¿qué condiciones deben cumplirse para que la acción de un ser humano produzca una irritación inaceptable, mediata o inmediata, en otro $?^{5}$ La primera y más evidente es la vida comunitaria, es decir, el hecho -si se quiere fatal- de compartir los seres humanos el mismo ambiente físico y simbólico. A un hombre aislado le sería imposible cometer una injusticia, como también sería imposible que alguien cometiera una injusticia en su contra. Pero, incluso viviendo en sociedad, la injusticia sería imposible si los hombres fueran iguales de manera sustancial y perfecta entre sí, o si la existencia de recursos fuera ilimitada. Los hombres son diferentes entre sí de manera radical -persiguen y requieren objetiva y subjetivamente fines y cosas distintas-, y los recursos disponibles son escasos. Esto se refiere por supuesto a las condiciones que Hume denomina circunstancias de la justicia, mismas que, según se alcanza a ver, lo son porque de manera más fundamental constituyen las condiciones de posibilidad de la injusticia. Y en tercer lugar, aunque de manera predominante por su importancia, para que una irritación sea considerada una injusticia -y estar así en condiciones de desatar y justificar una acción técnica para eliminarla-, su rechazo debe estar fundado en razones disponibles para quienes compartan ese ambiente físico y simbólico-cultural ${ }^{6}$.

\footnotetext{
${ }^{3}$ Un sistema técnico es trabajo dirigido a la transformación de objetos o situaciones concretas, físicas o simbólico-culturales, y orientado hacia la obtención de un resultado que a priori es considerado útil por el agente. Se constituye mediante decisiones o elecciones humanas en torno a medios, instrumentos, objetivos, fines, contextos de operación y resultados efectivos, y se evalúa por la libertad que permita o produzca para sus agentes.

${ }^{4}$ Aunque no de manera expresa ni detallada, es posible hallar ya esta interpretación en Dewey (2004).

${ }^{5}$ Es necesario insistir en que, desde el naturalismo filosófico, me estoy refiriendo a un concepto jurídico de la justicia y, por tanto, a un concepto de justicia en la escala humana; o, para decirlo con Rawls, a la justicia política, no metafísica.

${ }^{6} \mathrm{La}$ ciencia y la tecnología hoy hacen que ese ambiente tienda a coincidir con el planeta entero. Por ello sería necesario concebir a la justicia en términos universales, y la enunciación de sus reglas y su ejecución mediante un instrumento técnico distinto al Estado nacional hoy existente. Este asunto apunta hacia el cosmopolitismo, y no podrá ser tratado en este documento.
} 
En este sentido básico con el concepto de justicia se expresa la necesidad humana de coherencia y regularidad respecto a la conducta de otros seres humanos y sus resultados; una necesidad de racionalidad en su sentido de proporción, de ratio. Esa irritación en que se manifiesta la injusticia, ya se dijo, es una forma de violencia antropogénica. Eliminar esa irritación es el objetivo de la justicia como acto técnico. Es en tal sentido que la producción técnico-política de justicia liberaría a los hombres de la violencia?

Como estado de cosas valorado, alcanzable de manera intencional, la justicia ha sido definida desde la época clásica como el dar a cada quien lo que le sea debido ${ }^{8}$, como un poner los asuntos humanos en el lugar que le correspondan. Ese orden gregario justo fue encargado a la política (politeia) y, de forma más precisa, al Estado. Esto conduce a preguntar qué es eso que se le debe dar a cada quién en cada caso (una recompensa, un castigo o nada), cuánto de eso ha de suministrársele y, sobre todo, por qué; preguntas cuyas respuestas dependen del contexto cultural en que se les formule.

Esos criterios de la justicia cambian en la historia. En algún momento, por ejemplo, la compra-venta de seres humanos como esclavos fue considerada justa. En algunas culturas es considerado justo el trato discriminatorio hacia grupos minoritarios, o a las mujeres. La ley del talión es otro criterio de justicia que hoy nos parecería inadmisible. Para algunos filósofos y economistas, Nozick y Friedman los más conspicuos entre ellos, es justo lo que se obtiene mediante el ejercicio de la simple libertad de elección. Para otros filósofos y economistas, Rawls y Sen por ejemplo, es justo el acceso a los bienes primarios que posibilitan la igualdad de oportunidades para el ejercicio de la razón y de la libertad positiva de los individuos. Si bien puede hallarse un relativo consenso entre juristas y filósofos sobre el valor justicia como ese dar a cada quien lo que le sea debido, será en relación a su segunda dimensión filosófica -la de los criterios o reglas, siempre establecidos por convención-, donde surgen los principales problemas y desacuerdos. La legislación y sus procesos ${ }^{9}$ aparecen ahí como el campo problemático técnico-político de la justicia, y aquí es donde el Derecho ha de ser visto como instrumento técnico. Su objetivo concreto es normar las acciones humanas para producir determinados resultados considerados justos y evitar otros considerados injustos.

\footnotetext{
${ }^{7}$ Tras esta idea está Hobbes, sin embargo la noción pragmatista de contrato social no consiste en el sometimiento ante el Levia tán, sino en una permanente crítica y reconstrucción de la democracia y del Estado a través de la participación del público, y en atención a la libertad de los individuos que lo componen (Dewey, 1927).

${ }^{8}$ En República (Libro I, 331 e) Platón hace a Polemarco definirla así. Ahí mismo Trasímaco la define como aquello que conviene al poderoso, visión que, según comentaristas, era la opinión dominante de su tiempo -y en la actualidad coincidiría con el concepto de la legalidad formal-; y que Glaucón haga lo propio definiéndola, en términos contractualistas, como aquello mejor que pueden hacer los hombres para evitar las injusticias (Cfr. República, 559 a). La definición de Polemarco es retomada por Ulpiano, quien define el arte de lo bueno y lo justo como 'vivir de forma honrosa y acreditada, no perjudicar a los demás y dar a cada uno lo suyo'. Por motivos pragmatistas me apegaré a esta última concepción.

${ }^{9}$ La justicia se conecta con la democracia y la legitimidad en torno a la participación del público en la legislación, en el ser capaces de darse y seguir sus propias leyes, i. e., en la autonomía (Dewey, 2004).
} 
Dar a cada quien lo que le sea debido es darle su merecido, tanto en la acepción del uso común referida a una pena o castigo (justicia correctiva), como en el de merecimiento, mérito o recompensa (justicia conmutativa, retributiva o distributiva). Pero, cualquier cosa que se juzgue merecido por alguien, lo será en virtud de un acuerdo convencional al respecto. No hay algo preestablecido, absoluto o eterno que alguien merezca. No habría algo justo 'en sí mismo', como no hay algo verdadero 'en sí mismo'. Desde el punto de vista pragmatista lo que alguien merece depende, por un lado, de su práctica y sus resultados, y por otro, del contexto o medioambiente simbólico cultural en que es posible llegar a un juicio convencional y público sobre las condiciones y resultados de esa práctica. Escribe Dewey: “[e]l significado de justicia, en casos concretos, es algo que debe determinarse viendo qué consecuencias acarrearán bienestar a los hombres" (2004, p. 131). La justicia no tiene un contenido específico a priori, y hay que determinarlo en el contexto situacional de cada caso juzgado. Pero aunque convencional, la justicia es un acto de valoración que adquiere su estatus de valor por los resultados a que conduzca, resultados que se establecen y determinan en el intercambio de razones, en el uso público de la razón. Se sigue que el Derecho -el enunciado de las reglas para producir la justicia- es un instrumento técnico que ha de adecuarse al concepto de justicia que se tenga en cada contexto sociocultural.

Por otro lado, el concepto amplio de justicia como técnica ${ }^{10}$ tiene sentido aquí sólo aplicado a las acciones y sus resultados. La justicia como acto es entonces un asunto humano en seguimiento de la ley, es decir, del Derecho como reglas técnicas para la eliminación de la injusticia. Igual que racionalidad, justicia se predica de un hombre o de un grupo humano sólo de manera derivativa. En sentido estricto no hay individuos racionales o irracionales, sino prácticas racionales o irracionales. Tampoco habría en sentido estricto individuos o grupos justos o injustos, sino prácticas, individuales o colectivas, justas o injustas ${ }^{11}$. Y porque justicia se predica de la acción práctica, y nada más que de ella, es que requiere y permite un análisis pragmatista.

He argumentado en otro lugar que el fin de toda técnica es la libertad (Fisher, 2010). Esta idea de libertad, a diferencia de algunas consideraciones que se hacen desde la filosofía política y que suelen contraponerla a la justicia, más bien conjunta libertad $¥$ justicia. Quiero decir con esto que el concepto de libertad -desde el que

\footnotetext{
${ }^{10}$ Hay una diferencia fundamental con la conceptualización aristotélica: técnica (techné) no es nada más la del artesano (causa eficiente) que transforma materia inerte (causa material) produciendo un artefacto (causa formal) que cumpla una función o satisfaga un fin (causa final). Técnica aquí subsume toda práctica intencional sobre el mundo físico o simbólico, de tal manera que subsume, además de la artesanía, a la ciencia, a la tecnología, a la economía y, por lo que hace a los intereses de este ensayo, a la política misma. Sólo a esta última Aristóteles la consideraba como praxis dirigida por las virtudes morales. Requerimos abandonar esa distinción esencialista, pues poner artefactos físicos o simbólicos en el mundo es ponerlos entre los hombres, y, por tanto, dada la relación entre organismo y ambiente, toda práctica que afecta al ambiente afecta al organismo, en este caso al ser humano. La prudencia y la justicia entonces no nada más se requieren en la política, sino en la técnica en general.

${ }^{11}$ Esta coincidencia lógica extensional del ámbito de predicación de racionalidad, libertad y justicia en el campo de lo que es específico y distintivo de lo humano, no es contingente. Deriva de manera necesaria de una ontología relacional identificada en y con la práctica. Esto apunta el sentido en que tesis como la de Gehelen (1993) y Ortega (2005) resultan acertadas al considerar a la técnica como lo propio y distintivo del ser humano. Más aún, apuntala la tesis aquí sostenida de que la antropología filosófica -esa reflexión sobre lo que el hombre es, y puesto que el hombre es lo que hace- coincide con la filosofía de la técnica.
} 


\section{Quaestio Iuris}

toda aplicación técnica parte y hacia el que toda aplicación técnico-política legítima se dirige- es radicalmente inseparable del de justicia. De un modo más familiar -o al menos familiar para los filósofos- puede decirse que "la justicia sin libertad es vacía y que la libertad sin justicia es ciega”. En el concepto pragmatista de libertad aquí propuesto se conjuntan:

1. la ausencia de constreñimientos físicos o sicológicos para llevar a cabo determinadas prácticas (libertad negativa, freedom),

2. las capacidades físicas y culturales efectivas para llevar a cabo funcionamientos valiosos (libertad positiva, poder efectivo, o lo que en inglés refiere el verbo can), y

3. la legitimidad o aceptabilidad racional de los resultados de esas prácticas (liberty, o lo que rescatan algunas expresiones en inglés utilizando el verbo may).

Justicia es esa condición general -el así llamado bien común- que permite producir y expresar la libertad del individuo. Es en este sentido que la legitimidad del Estado depende de qué produzca para sus ciudadanos. Esta idea es sostenible si, como hace el pragmatismo, se superara el dualismo individuo-sociedad, dualismo que conduce a la oposición entre libertad y justicia. Su relación con el concepto de Estado, o sistema político (Easton, 1981) como sistema técnico, puede expresarse en un condicional: si la libertad es el fin de todo sistema técnico en general, entonces la justicia es el objetivo propio y central del sistema político en particular. Si un sistema político permite o produce condiciones inequitativas en la asignación de valores (poder, ingreso, oportunidades y en general los bienes básicos), entonces disminuye la libertad (capacidades) de al menos algunos de sus ciudadanos, haciendo que esa asignación no sea autoritativa; el Estado será entonces ilegítimo, irracional; y lo será a causa de ser injusto.

El Estado (organización política del público) se propone fines individuales (la libertad) a través de medios y objetivos colectivos (la justicia) ${ }^{12}$. En otras palabras, la libertad nada más puede producirse y sostenerse a través de la justicia, mediada por la acción social y a través del Estado (Dewey, 1935). La acción social política tiene como fin la libertad, y la justicia es su objetivo práctico inmediato: si no hay contraposición entre individuo y sociedad, tampoco puede haberla entre libertad y justicia, que definirían entonces la calidad de vida (Sen, 2002a y $2002 b)^{13}$.

Se asume entonces un concepto naturalizado de "libertad" tal como es experimentada. Esto tiene relevancia filosófica y pertinencia práctica porque, entre otras cosas, permite explicar cómo el hombre de hecho puede elegir entre rumbos de acción incluso ante problemas de radical indecidibilidad 'racional', como en el

\footnotetext{
${ }^{12}$ Tal es, por ejemplo, la idea de H. Croly -citada por Del Castillo (2003, p. 30)- de "alcanzar fines jeffersonianos a través de medios hamiltonianos."

${ }^{13}$ El enfoque de capacidades (libertad positiva) de Sen permite entender el concepto de libertad aquí sostenido y por qué se le propone como baremo para evaluar la técnica en general y la política en particular
} 


\section{Quaestio Iuris}

conocido ejemplo de Buridan. El hombre tendría libertad por tener el poder de suspender el razonamiento y ejercer, más que su libre albedrío, su libre arbitrio, es decir, de realizar un juicio absolutamente arbitrario, i. e., libre en el más radical sentido posible para la escala humana, y tomar una decisión (elegir) precisamente ahí donde la simple razón algorítmica no alcanza para hacerlo. La propuesta pragmatista sobre el concepto de libertad conduce a una naturalización del concepto mismo de razón humana.

La literatura filosófica ha sido abundante sobre el tema ${ }^{14}$. Libertad se predica en primer lugar de la capacidad que el hombre tiene para actuar o no actuar de determinada manera. Por ejemplo, si quiero escribir este ensayo, entonces lo hago (como podía muy bien haberlo evitado), tal y como el lector puede leer hasta esta línea y detenerse, o bien puede seguir adelante, si así lo decide. Esta libertad individual, como poder hacer no sujeto a constreñimientos coincide con la libertad negativa.

La primera consecuencia del planteamiento naturalista es la inexistencia de una sustancia o esencia que se llame libertad, de manera análoga a como no existe una esencia o sustancia que se llame verdad. Así como la verdad es una relación entre los enunciados y las evidencias disponibles a los sentidos humanos, la libertad es una nota distintiva de la relación transaccional del ser humano y su entorno. No se dice que hay una verdad sino que hay enunciados verdaderos o falsos. No podemos hablar de una libertad, sino, en su caso, de prácticas humanas libres o no. Hablamos en ambos casos de relaciones y no de sustancias. La libertad adjetiva a ciertas acciones, como la verdad a ciertos enunciados, y la racionalidad a ciertas prácticas.

Una segunda consecuencia del planteamiento naturalista es referir la libertad sólo al espacio de lo física y lógicamente posible. Libertad no aplica donde hay imposibilidad. Un hombre no es 'libre' de volar (se entiende que en ausencia de todo tipo de artefactos) porque no le es físicamente posible. Un hombre no es 'libre' de estar $y$ no estar en un momento y un lugar determinados porque no es lógicamente posible. Carece de sentido plantearse la libertad donde no existe posibilidad de su ejercicio.

Esto conduce, entonces, a caracterizar la libertad como un poder de hacer, es decir, como posibilidad efectiva del hombre para llevar a cabo una determinada práctica. La llamada libertad positiva, o libertad para (Sen). Se refiere a las habilidades adquiridas y/o a la dotación de los medios para llevar a cabo determinados cursos de acción. La simple ausencia de constreñimientos o libertad negativa, aunque necesaria, no es suficiente para la realización de la práctica. Un sujeto, individual o colectivo, puede ser autónomo $¥$ carecer de recursos o

\footnotetext{
${ }^{14}$ En Hume es claro el vínculo entre inducción, certeza, causalidad, libertad y límites de la razón humana. En el siglo XX Duhem y Neurath propusieron los conceptos de 'buen sentido' y 'motivos auxiliares' (de la razón), respectivamente, para indicar tanto que la razón es insuficiente y limitada para tomar decisiones, como para corroborar que su ejercicio, i. e., la racionalidad, sólo es po sible en y por la libertad de la voluntad humana. No obstante, aunque se pueden elegir razones distintas para sostener y refutar algo -puesto que cada individuo ejerce su libertad de manera radicalmente subjetiva y autónoma-, queda algo en común a lo que apelar como base de los acuerdos: la experiencia -compartida por los sentidos y compartible por el lenguaje- de los resultados observables de aquello sobre lo que se está en desacuerdo (acciones, creencias, valores, prácticas y sistemas técnicos).
} 
habilidades para llevar a cabo las acciones que decida. Si una persona se encuentra física y sicológicamente libre de constreñimientos pero carece de las habilidades mínimas o los recursos necesarios para realizar una acción, entonces no podrá realizarla, y la existencia de su libertad negativa será irrelevante respecto a la acción considerada.

Si la capacidad efectiva para realizar determinados actos, o libertad para, tiene su base en la ausencia de constreñimientos, o libertad de, entonces puede decirse que la libertad de sin la libertad para es irrelevante, y que la libertad para sin la libertad de es nula. La libertad es negativa ұ positiva, o no será libertad en absoluto.

Hay un tercer y crucial aspecto desde el que el concepto de libertad que intento proponer requiere ser establecido y acotado, a saber, el de su legitimidad. Como en castellano no existe el vocablo correspondiente hay necesidad de recurrir al término inglés liberty. ${ }^{15}$ Decimos que somos libres respecto a una práctica cuando esa práctica es socialmente aceptada como legítima, es decir, cuando no sólo es de hecho aceptada, sino que además es aceptable por buenas razones. E. g., aunque tengo libertad de (freedom) (puesto que nada ni nadie me obstaculiza), y para conducir un auto (puesto que poseo un auto y la habilidad para conducirlo) bajo un estado alterado de conciencia (pongamos por caso el de ebriedad), no estaré en plena libertad (liberty) de hacerlo, pues esa práctica no sólo no es socialmente aceptada, sino que es castigada, además de ser peligrosa para un público, es decir, es inaceptable por buenas razones. Este concepto de libertad (liberty), como legitimidad o autorización de y para llevar a cabo una práctica, es lo que vincula la libertad individual en una persona con la colectividad, i. e., en un ser humano socializado, y tiende el puente conceptual básico entre la libertad individual y la colectiva, cosa central en torno a su relación con la justicia.

Hay prácticas que, con relativa independencia del poder hacer técnico que las posibilitan, pueden pasar de ser legítimas a ser ilegítimas, y viceversa. Un rasgo importante de este tercer aspecto de la libertad es su carácter convencional y vinculado a un cierto estado de evolución y desarrollo de la cultura. Mientras que la libertad de y para (freedom) se asocia causalmente a poderes físicos, materiales o sicológicos, la libertad como legitimidad (liberty) lo hace con aspectos propiamente simbólicos y culturales. De aquí surge la idea, al parecer correcta, de que la libertad como poder o potencia de hacer algo se encuentra moldeada culturalmente por la autorización colectiva (legitimidad) de y para hacerlo, es decir, por el considerar y sopesar otros valores inseparables de su ejercicio y, en el caso particular de la política, con la justicia.

Es así que el concepto de libertad aquí sostenido tiene un carácter relacional, no sólo entre ausencia de constreñimientos y capacidades efectivas, sino respecto a la legitimidad de las prácticas sobre las que ese concepto sea predicable. Libertad no es una sustancia inamovible ni una idea eterna o perfecta, sino un adjetivo que se predica, en todo caso, sobre determinadas prácticas humanas accesibles a la observación empírica bajo un

\footnotetext{
${ }^{15}$ Una aclaración de este término puede encontrarse bajo la entrada "Freedom and Liberty", de Feinberg, J. , en la Routledge Encyclopedia of Philosophy.
} 


\section{Quaestio Iuris}

contexto sociocultural dado. Ha de tenerse presente que esa libertad que posibilita a una práctica y que cualifica la vida de su agente, puede ser ampliada o reducida como resultado de la misma práctica técnica. Y de aquí que esa libertad sea un valor susceptible de utilizarse para la evaluación de sistemas técnicos como el Estado.

\section{UNA JUSTICIA NATURALIZADA: JUSTICIA E IGUALDAD, EQUIDAD E IMPARCIALIDAD}

Dos ideas generales se siguen de lo anterior. La primera concibe todas y cada una de las tres dimensiones de la justicia como expresiones de cierto concepto de razón, que es el de proporción o, como ya se apuntó, el de ratio $^{16}$ : el valor (dar a cada quien lo que le sea debido), la regla que enuncie ese valor (la Ley), y el acto que la realiza (ejecutar una corrección o una distribución) expresan un sentido de la proporción sobre los asuntos humanos, un buen sentido que puede entenderse como equidad y como imparcialidad. Vuelvo a esto líneas abajo. La segunda idea general, simultánea y paralela, consiste en ver la justicia como un medio y un objetivo, como algo que ha de construirse en y a través del sistema político qua sistema técnico, sistema que, por tanto, será él mismo susceptible de evaluarse por los resultados que su ejercicio produzca para el hombre y, como ya se dijo, en particular para las condiciones que definen la libertad humana ${ }^{17}$.

Desglosemos ahora la primera de estas dos ideas generales para intentar ver sus implicaciones lógicas y prácticas más fundamentales. La justicia como proporción, como ratio, refiere a un concepto convencional de la misma: no hay algo que sea lo justo o lo injusto porque no hay algo que sea lo proporcionado o lo desproporcionado. Estos adjetivos, cuando califican una relación entre los seres humanos, lo hacen desde un contexto sociocultural que es el que valida o no su aplicación al caso tratado. Las relaciones humanas son importantes porque en esas relaciones puede presentarse la irritación que denominamos injusticia, y es a partir de este tipo de irritaciones empíricas es que podemos:

1. imaginar y valorar un estado de cosas distinto como justo o proporcionado,

2. enunciar una regla (la Ley expresa en el Derecho) que permita alcanzarlo, y

3. ejecutar el acto técnico-político que elimine o prevenga esa desproporción.

En concordancia con el naturalismo justicia e injusticia tendrían, pues, un carácter convencional, de la misma forma que las nociones de verdad y falsedad en epistemología. No hay una práctica, o un estado de cosas resultado

\footnotetext{
${ }^{16}$ Esta concepción tiene su origen en Aristóteles: "Lo justo, entonces, es la proporción, y lo injusto lo que va contra la proporción (... ) esta justicia es un término medio en la proporción, porque lo proporcional es un término medio y lo justo es proporcional”. Ética a Nicómaco, 1131b, Gredos.

${ }^{17}$ En la filosofía política contemporánea hay posiciones próximas a ésta, si bien sostenidas por distintos motivos y diferencias entre ellos, por Rawls (1995) y Walzer (1993). La justicia como objetivo técnico del derecho como instrumento es un tema planteado y explorado por Bunge (2000) y Alexy (2003).
} 


\section{Quaestio Iuris}

de esa práctica, que sea LO justo o LO injusto. Todo lo que tenemos son procesos y estados de cosas que nos aparecen y valoramos como justos o injustos, i. e., aceptables o inaceptables, por diversas razones públicas y bajo determinado contexto ${ }^{18}$.

El problema entonces no es definir qué es la justicia de una vez para siempre en términos de condiciones necesarias y suficientes, sino más bien acordar dos cosas vinculadas:

1. la manera de identificar y delimitar la presencia de una injusticia, $y$

2. establecer un método aceptable para eliminarla mediante la técnica, para hacer justicia, es decir, para de forma operativa y efectiva dar a cada quien lo que -según cada caso- le sea debido.

Hay que producir o hallar las razones que permitan responder qué y por qué determinados seres humanos merecen eso que haya de dárseles, considerando que:

1. lo que se les dé siempre es escaso, y

2. que los individuos no son iguales $y$, por tanto, que no merecen ni necesitan lo mismo.

Y aquí, como Sancho y don Quijote con la iglesia, con la igualdad hemos topado.

Tanto en la filosofía como en el sentido común (y esto corrobora que ninguno de los dos conocimientos implícitos ahí sea infalible) suele (mal) entenderse por justicia una cierta idea de igualdad, esa misma que -junto a la libertad y la fraternidad- forma parte central en los ideales políticos de la Ilustración ${ }^{19}$. Parecería como si la justicia fuera identificable en la igualdad, como si hubiera justicia sólo ahí donde hay igualdad. Esto implica que la injusticia sería toda aquella situación en la que los hombres no fueran iguales; cosa que es problemática porque en efecto los seres humanos no son iguales ni lo pueden ser, y si injusticia fuera esa desigualdad entre los hombres entonces el asunto de la justicia desaparecería como problema.

Igualdad es una relación. Bien, entonces ¿igualdad con respecto a qué? Los hombres pueden ser iguales en relación a su estatura, su peso o su edad, su color de piel o su lugar de nacimiento. Desde el punto de vista lógico todos los hombres son iguales en el sentido de que todos son mortales. Pueden ser (más o menos) iguales respecto a determinados comportamientos, como cuando algunas mujeres afirman que "todos los hombres son iguales". De manera más interesante desde el punto de vista político-en la tradición de Hobbes y Hume-, se dice que los hombres son iguales en fortaleza, en el sentido nada trivial de que cualquier ser humano puede asesinar o

\footnotetext{
${ }^{18}$ Dice Pascal (1993, p. 38) que así '[c] omo la moda hace el agrado, así hace la justicia’, una idea que después desarrollará Hu me, y de la que Dewey partirá en su Teoría de la valoración. La moda a la que Pascal se refiere ha de interpretarse como la opinión pública en su sentido estadístico: justo es lo que la comunidad política cree o siente que es justo. Esto no hace que el concepto de justicia sea arbitrario, sino convencional. Como las creencias se forjan en la sociedad y en la cultura, se sigue que los criterios de la justicia cambian con la historia y las culturas. Esto es relacional, no relativo: que lo identificable y aceptable como justo o verdadero dependa del contexto cultural no significa que cualquier cosa valga como justa o verdadera.

${ }^{19}$ Conviene tener en cuenta que estos ideales coinciden con los principios rawlsianos de la justicia, y que siguen siendo válidos por seguir siendo pertinentes.
} 
ser asesinado por otro (Hobbes, 1998, Cap. XIII, p. 100). Pese a estos usos, el naturalismo es incompatible con toda idea de igualdad sustancial. Los individuos somos diferentes. No es que tengamos derecho a serlo. Este es un dato, un hecho empírico con que topamos y a partir del que, como apunta Hume y recuerdan filósofos variopintos, se ha de pensar la justicia. Ésta no consiste entonces en igualar en sentido alguno a los seres humanos (la expresión misma carece de sentido ${ }^{20}$. Los hombres son diferentes entre sí, por ejemplo, en talentos, riquezas, habilidades, vocaciones, intereses, posición social, etc. Una situación justa, pues, no es ni podría ser un reclamo o pretensión de igualdad sustancial de los individuos respecto a nada. Por eso la justicia tiene que ser entendida como proporción, como ratio-nalidad, es decir, como una equidad característica que pueden adquirir o perder las condiciones y resultados de las transacciones humanas, y no como igualdad sustancial de los agentes involucrados en ellas. El problema de la justicia -qua problema técnico- no es el de igualar a los individuos respecto a una característica determinada, sino el de alcanzar una simple equidad en sus relaciones. Producir justicia refiere entonces al control y ajuste de las relaciones que establecen entre sí los individuos, y no de sus características físicas, mentales, sociales o culturales.

Pero aunque la noción de 'equidad' es, por decirlo de alguna manera, más natural que la de 'igualdad', no está ayuna de problemas. En castellano se ha utilizado equidad para verter el término inglés fairness ${ }^{21}$ que, para muchos filósofos, debería traducirse más bien por imparcialidad. Aunque en inglés suelen usarse ambos como sinónimos conviene precisar su uso en castellano, al menos para los limitados alcances de este ensayo. Una clave para distinguir equidad de imparcialidad la hallamos en Perelman (1964. p 19 y ss.). Enumera ahí hasta seis fórmulas (las pautas de Nozick) o criterios por medio de los cuales suele intentarse enunciar lo que es justo, criterios, pautas o fórmulas en general incompatibles entre sí (por ejemplo, 'a cada quien según sus necesidades', 'a todos la misma cosa', o 'a cada quien según sus obras'). Perelman se pregunta si es posible algún denominador común que permita superar tanto una posición que niegue todo criterio concreto de justicia, haciendo que todo valga, como otra que se aferre a una de ellas como dogma y niegue a las demás. Así, llega a una concepción formal de la justicia partiendo de lo que denomina una característica esencial que, como tal, definiría a un conjunto de individuos dentro de una misma categoría pertinente que justifique tratarlos de manera igual: 'Se puede definir (...) la justicia formal y abstracta como un principio de acción de acuerdo con el cual los seres de una misma categoría esencial deben ser tratados de la misma manera' (p. 28, resaltado mío). Pero, desde luego, como el mismo autor advierte enseguida, "el desacuerdo nace al tratar de determinar los caracteres esenciales para la aplicación de la justicia" en casos concretos, puesto que los hombres pertenecen a, o pueden ser clasificados dentro de diversas

\footnotetext{
${ }^{20}$ En esta imposibilidad adquiere paradójico sentido la conocida frase de Orwell en Animals Farm, según la cual 'todos somos iguales pero unos somos más iguales que otros'.

${ }^{21}$ El caso paradigmático es el de Andrés de Francisco, quien vierte Justice as Fairness por La justicia como equidad. vol. 08, nº. 04, Número Especial. Rio de Janeiro, 2015.pp. 2532-2555 


\section{Quaestio Iuris}

categorías esenciales, es decir, son diferentes entre sí. No parece posible una única y definitiva fórmula que pueda aplicarse de manera universal. De ahí que, afirma Perelman:

"[c]uando las antinomias de la justicia aparecen y la aplicación de ésta nos obliga a transgredir la justicia formal, se recurre a la equidad. A ésta se le podría considerar como la muleta de la justicia, y es el complemento indispensable de la justicia formal siempre que su aplicación resulta imposible. Consiste en una tendencia a no tratar de manera demasiado desigual a los seres que forman parte de una misma categoría esencial (...), tiende a disminuir la desigualdad ahí donde el establecimiento de una igualdad perfecta, de una justicia formal, se vuelve imposible por el hecho de que simultáneamente se toman en cuenta dos o más características esenciales que chocan en ciertos casos de aplicación" ${ }^{\prime 22}$ (p. 46, cursivas en el original, negritas añadidas).

Como los hombres no son iguales y el tratarlos de manera igual conduce a antinomias (dar trato igual a desiguales transgrede el sentido de la justicia, de la ratio), no tenemos más que la equidad como recurso para conducir la práctica humana en la vida cooperativa. La equidad es una característica que pueden adquirir las condiciones y resultados de las relaciones establecidas entre los hombres, y no lo hombres mismos. Esta equidad entre los seres humanos que constituyen una comunidad política constituye esa justicia perseguida por la técnica, por la política a través del Derecho en sentido estricto. La medida y el peso específico en que una determinada característica esencial haya de ser tomada en consideración en un acto técnico de justicia (correctiva o distributiva) en casos concretos, es un asunto que desde luego tiene que resolverse casuísticamente, intercambiando y sopesando las razones contextuales particulares, labor en la que la prudencia tiene importancia fundamental. Es en este sentido que equidad es expresión de ratio, de una proporcionalidad, permitiendo decir que la justicia expresa la eficiencia sistémica de la práctica política, desde el punto de vista de la aceptabilidad por buenas razones (legitimidad) de los resultados de ésta.

Aunque son conceptos distintos, imparcialidad y equidad tienen relevancia filosófica, moral y política en torno al problema de la justicia, y son, en este asunto, inseparables (aunque distinguibles): justicia como equidad hace referencia al fin de la acción que produce la justicia: se refiere a transformar una situación humana $S_{1}$ considerada deficitaria (inequitativa) en una $S_{2}$ considerada satisfactoria, o al menos mejor (equitativa, o menos inequitativa). Imparcialidad, por su parte, hace referencia más bien al juicio del agente que juzga en tanto que juez (referee, umpire) de las relaciones humanas. Equidad, igualdad compleja (Walzer, 1993), o justicia como proporción en los asuntos humanos- se predica de las relaciones humanas, mientras que imparcialidad se predica del juicio del hombre (en general por eso constituido en juez) respecto a las condiciones y resultados de determinadas acciones o relaciones humanas. El juicio imparcial ha de ejercerse sobre las condiciones y resultados

\footnotetext{
${ }^{22}$ Michael Walzer (1993) es quizá el filósofo contemporáneo que más se aproximaría a una concepción pragmatista de la justicia como acto. La entiende como una igualdad compleja, cosa que coincide con la equidad de Perelman (1964). Las esferas de la justicia en Walzer refieren de hecho a las categorías esenciales de Perelman, puesto que las primeras se definen por la pertinencia de las características que han de tomarse en cuenta al dar a cada quien lo que, según el caso, le sea debido.
} 
de las relaciones humanas, es decir, sobre su equidad o inequidad. Estas relaciones pueden ser o no equitativas, y la imparcialidad del juicio se refiere a que quien lo ejecuta no tome partido al margen de esas reglas y criterios acordados por convención, es decir, del Derecho. La imparcialidad tiene que ver con observar y sopesar sólo las esferas de la justicia (Walzer) o las categorías esenciales (Perelman) pertinentes a cada caso juzgado. Si las relaciones humanas y la estructura básica de la sociedad, por ejemplo, producen que un diputado perciba un salario varias veces superior al de un profesor, y si no hay razones disponibles para dar a cada quien ese salario, es decir, si ninguno de los dos merece eso que se le da, aparecerá entonces una irritación, sobre todo en el profesor, pero también en quienes observen de forma imparcial esas relaciones, que serán entonces calificadas como no equitativas, y en consecuencia, requerirán de un ajuste técnico (político) en el sentido de la justicia, i. e., de producir la equidad mediante la aplicación de la norma jurídica y, en su caso, en el ajuste y modificación de ésta misma norma.

Por eso se habla de relaciones equitativas (o no) y de juicios imparciales (o no), y, como toda transacción es equitativa o no sólo para alguien que juzga al respecto, y como todo juicio pertinente sólo lo es respecto a la equidad o no de una transacción, entonces es claro que en las circunstancias de la justicia (o de la injusticia) equidad e imparcialidad no pueden separarse, lo cual no implica que puedan confundirse o tenerse como sinónimos.

La equidad de las relaciones entre los ciudadanos es sancionada y considerada entonces por la imparcialidad en la acción del juez. La imparcialidad del juicio tiene que ver con la llamada justicia correctiva, es decir, con la distribución de castigos y compensaciones. Pero la teoría de la justicia como equidad (justice as fairness) se avocó más bien a una dimensión política de la justicia distributiva o social (libertad, igualdad y diferencia, o fraternidad) más que al caso concreto, aunque también político, de la justicia penal. De ahí que la traducción castellana de fairness por equidad y no por imparcialidad se justifique, toda vez que la justicia social tiene que ver más con el logro de esa equidad en las relaciones sociales que con la imparcialidad de un juez que distribuye castigos y compensaciones ${ }^{23}$.

Podemos entonces afirmar que en filosofía moral y política una igualdad sustancial de los seres humanos sería un análogo de la concepción correspondentista y metafísica de la Verdad en la teoría del conocimiento: ninguna de ellas tiene sentido. De ahí que el análogo moral y político posible de la verdad sea la equidad, lo que hace ver de inmediato que la imparcialidad sería el análogo de la objetividad como intercambio convencional de descripciones razonables acerca de las condiciones y resultados de las relaciones establecidas entre los seres

\footnotetext{
${ }^{23}$ Fairness como imparcialidad cabría sólo en torno a la posición original y el velo de ignorancia rawlsianos. Es obvio que en ese contexto Rawls estaba preocupado por una objetividad absoluta, por una imparcialidad accesible en la hipotética situación original contractualista, pero el interés y el fin práctico fundamental de la justicia como acto de corrección es la consecución de relaciones humanas equitativas. Creo por ello justificado y válido en ese contexto verter el término inglés fairness por el castellano equidad.
} vol. 08, nº 04, Número Especial. Rio de Janeiro, 2015. pp. 2532-2555 


\section{Quaestio Iuris}

humanos, es decir, como intersubjetividad. Justicia sería así una característica empírica, posible y deseable en las condiciones y resultados de la práctica transaccional de los individuos que constituyen una sociedad.

La tradición filosófica suele pensar la justicia como virtud (de los individuos o de los grupos), y separarla esencialistamente entre distributiva y correctiva, derivándose de esto en ocasiones una contraposición entre justicia y libertad ${ }^{24}$. Se afirma, por ejemplo, que la libertad económica para perseguir el propio interés puede conducir, y de hecho conduce, a la injusticia social; y, viceversa, que abogar por una justicia social -por ejemplo, la redistribución del ingreso- afectaría la libertad y los derechos de aquellos agentes más eficientes que, por ello, merecerían o habrían obtenido el derecho a mantener una posición privilegiada ${ }^{25}$.

La injusticia aparece junto al público de una práctica (Dewey, 2004) ${ }^{26}$, y de ahí que la procuración de justicia -tanto en sentido negativo de prevenir la injusticia, como en el sentido positivo jurídico de correctiva, o en el social de distributiva- sea un problema político fundamental y, por tanto, un objeto de atención formal del Estado, esa organización política del público. Desde este punto de vista la justicia aparece primero como una necesidad de corregir los resultados negativos (injustos), inmediatos o mediatos, de alguna práctica. Por esto es que en la historia tropezamos primero ante la necesidad de la llamada justicia correctiva, en general identificada con la aplicación del derecho penal, donde dar a cada quien lo que es debido consiste en castigar al agente y en indemnizar -en la medida de lo posible- a su víctima. Como ya se dijo, si el tema ha ido más allá del derecho pena ${ }^{27}$ es porque hay prácticas que producen injusticias sólo de manera mediata, a través de un proceso social e histórico de cambios y efectos sucesivos que es menester reconstruir para determinar la relación causal. Sufrimos una injusticia inmediata y sentimos necesidad también inmediata de corregirla cuando, por ejemplo, somos sometidos a los resultados directos e indeseables de la conducta de otro agente, como en el caso de un "atraco legal" (de un banco sobre su cliente, por ejemplo) o ilegal (de un asaltante sobre su víctima).Y sufrimos una injusticia mediata al percibir resultados indeseables e inaceptables, en nosotros o en algún otro ser humano, que no provienen en línea directa de un agente concreto, sino de manera oblicua, a través de una mediación que opera

\footnotetext{
${ }^{24}$ Nozick (1988) es el filósofo que más ha insistido en esta contraposición.

${ }^{25}$ Esta disputa básica enfrentó en la modernidad a socialistas y liberales (izquierda y derecha). Hoy enfrenta, en general con menos virulencia, a comunitarismo y liberalismo. Dentro de este último la disputa es visible entre un liberalismo social -en algunos aspectos cercano al pragmatismo-, como el de Rawls, y un liberalismo de corte 'anarquista' como el del propio Nozick.

${ }^{26}$ La distinción política entre lo público y lo privado se refiere a los resultados de una acción: cuando estos se restringen al propio agente es privada; cuando van más allá del agente se hace pública (produce un público) y requiere de atención política.

${ }^{27}$ Nótese sin embargo que ya este caso inmediato la justicia no es un asunto entre el agente y su víctima, sino de ambos respecto al público. La justicia correctiva no trata exclusivamente de castigar al primero y satisfacer a la segunda, sino de permitir al grupo social una relativa seguridad respecto a la racionalidad (proporcionalidad) de las relaciones que constituyen al grupo.
} 


\section{Quaestio Iuris}

sobre condiciones institucionales hoy existentes -aunque forjadas a partir de diversas prácticas pasadas. Rawls llama a estas condiciones la estructura básica de la sociedad. ${ }^{28}$

\section{LA JUSTICIA, RAWLS, NOZICK Y DEWEY}

John Rawls es sin duda el filósofo que más influencia ha tenido respecto al planteamiento e intentos de respuesta al tema filosófico de la justicia ${ }^{29}$. Aunque su posición de inicio en filosofía moral implica una ética deontológica incompatible con el pragmatismo consecuencialista, los principios de la justicia que a partir de aquella posición elabora y enarbola resultan compatibles con una filosofía política pragmatista e instrumentalista. Sostengo aquí que es posible alcanzar esos principios (libertad, igualdad de oportunidades, y diferencia) a partir de los resultados empíricos de la práctica, y necesariamente no desde el a priori kantiano de la posición original y el velo de ignorancia; es decir, me parece posible una readecuación de la teoría de la justicia rawlsiana en clave experimentalista ${ }^{30}$. Desde luego, esta empresa particular no puede ser llevada a cabo aquí; sin embargo, al respecto puede apuntarse lo siguiente.

Los supuestos de la posición original y el velo de ignorancia constituyen una especie de imagen en negativo de la teoría de la competencia perfecta en el análisis económico. En "competencia perfecta" los consumidores y productores tendrían un conocimiento pleno de los diferentes productos y factores que existen en cada momento en el mercado, y los agentes son racionales en el sentido de la maximización de su utilidad o beneficio, en concordancia con los presupuestos centrales de la razón instrumental ${ }^{31}$. Rawls transforma ese hipotético conocimiento económico perfecto en una ignorancia social y política perfecta producida por el velo, pero mantiene el supuesto de una racionalidad instrumental maximizadora. Desde esa situación hipotética deriva

\footnotetext{
${ }^{28}$ Los límites entre lo público y lo privado, es decir, los límites de lo justo, cambian con el cambio técnico. Hay razones para afirmar, por ejemplo, que los resultados de un sistema técnico de producción y distribución -que en algún momento se consideró justo-, a saber, el mercado del laissez faire, son hoy inadmisibles para un público que no participa como su agente, sino como su víctima, en todos los sentidos de este último término. Incluso comienza a tener resultados inadmisibles para sus propios agentes. Parece obvio que la justicia -en tanto asunto de atención política- cruzaría por la revisión, adecuación, ajuste o transformación, en el sentido de corrección, más o menos profunda de aquel sistema técnico.

${ }^{29}$ La relevancia filosófica de Rawls es puesta de manifiesto por quien es uno de sus más importantes críticos: Robert Nozick. Éste sostiene un liberalismo anarquista o de estado mínimo, en el extremo opuesto al liberalismo igualitario rawlsiano de corte intervencionista, y escribe: 'Ahora los filósofos políticos tienen que trabajar según la teoría de Rawls, o bien, explicar por qué no lo hacen.' (1988, p.183). Esta afirmación aplica al propio Nozick, quien no sólo escribe una extensa y meticulosa crítica a la Teoría de la justicia, sino que construye una alternativa basada en la teoría de los derechos de propiedad de Locke y en cierta interpretación del principio kantiano de autonomía individual. Entonces, para hacer filosofía política contemporánea, hay que decir por qué no se sigue a Rawls ұ por qué no se sigue a Nozick, amén de aclarar, como pretendo hacerlo aquí, por qué convendría seguir a Dewey. ${ }^{30}$ Esta parece ser la misma idea contractualista básica sostenida por Thomas Scanlon (1982), al rechazar tanto al utilitarismo protocomunitarista, como a toda justificación moral basada en la racionalidad instrumental típica de la teoría de la elección racional.

${ }^{31}$ Rawls (1979). Cap. I y II, en particular pp. 140-147. Es el concepto rawlsiano de racionalidad lo que conduce a apartarse de su método. Aunque Barry (1997, pp. 85-92) hace apasionada defensa de un presunto Rawls que tomaría distancia de la teoría de la elección racional, su esfuerzo es insuficiente.
} 
los principios que esos individuos racionales aceptarían signar para definir el comportamiento y operación de las instituciones que constituyen la estructura básica de la sociedad. Desde la formalidad lógica se le ha criticado que esos supuestos no nada más permiten derivar sus principios de la justicia, sino también otros, en particular los del utilitarismo, doctrina que de manera expresa el autor intenta refutar en su obra. Como Nozick muestra con acierto, Rawls se ve forzado a incorporar supuestos adicionales ad hoc con el fin de asegurar la derivación efectiva de sus principios.

En cualquier caso, los dos principios rawlsianos -desdoblados en tres ${ }^{32}$ - podrían derivarse en vía pragmatista y razonable desde y a través del intercambio público de razones, y a partir de la consideración de los resultados observables de la práctica humana:

1. la mayor libertad posible para el mayor número posible de individuos compatible con la libertad y autonomía de cada uno de ellos,

2. la igualdad de oportunidades, $y$

3. la aceptación de distribuciones y tratos desiguales o diferenciados que favorezcan a los peor situados, pueden ser sostenibles por buenas razones a la luz de los resultados concretos de la práctica humana, y no a partir de una posición original, puestos bajo el velo de ignorancia y como hipotéticos seres con racionalidad perfecta. Esos principios pueden acordarse a partir de las condiciones de la razón y la experiencia con las que cuenta un individuo real, como sostiene el naturalismo pragmatista ${ }^{33}$.

Quiero decir con esto que hay buenas razones para aceptar los principios rawlsianos de la justicia. Pero estas razones no son asequibles bajo un velo de ignorancia, ni para seres "perfectamente racionales", sino desde las simples condiciones naturales que enfrentamos, es decir, bajo un conocimiento falible -ni velo de ignorancia ni conocimiento perfecto y absoluto-, y desde la razón como mera capacidad biocultural para dirigir la conducta humana en general, y para valorar lo que es justo o injusto en particular. La crítica pragmatista a Rawls consistiría, por un lado, en que los principios de la justicia no pueden ni tienen porqué derivarse a priori, sino, más bien, a partir de las condiciones y resultados de la práctica humana; $y$, por otro, que si bien esos principios son razonables hoy, nada garantiza esto en el futuro. Vistos desde el naturalismo, esos principios son una conjetura práctica cuya

\footnotetext{
${ }^{32}$ Rawls (1996 p. 33) enuncia los siguientes principios ' 1 . Toda persona tiene igual derecho a un régimen plenamente suficiente de libertades básicas iguales, que sea compatible con un régimen similar de libertades para todos $[\mathrm{y}] \underline{2}$. Las desigualdades sociales y económicas han de satisfacer dos condiciones. Primero, deben estar asociadas a cargos y posiciones abiertos a todos en las condiciones de una equitativa igualdad de oportunidades; $y$, segundo, deben procurar el máximo beneficio de los miembros menos aventajados de la sociedad'. Camps (1996, p. 12) desdobla estos dos principios en tres, a saber, el de libertad, el de igualdad de oportunidades y el de diferencia (fraternidad).

${ }^{33}$ Es sostenible decir que así fue como de hecho procedió Rawls: halló y evalúo sus principios razonando respecto a los fenómenos observables, y después elaboró una narración "racional” (a priori en el sentido kantiano) desde la cual derivarlos y justificarlos.
} vol. 08, no. 04, Número Especial. Rio de Janeiro, 2015. pp. 2532-2555 
validez y legitimidad dependerá siempre de los estados de cosas que produzca el conducirse de acuerdo a ellos, dado un contexto sociocultural.

Rawls, por el contrario, parece ir en busca de lo inmutable. ${ }^{34} \mathrm{Y}$ de ahí que la derivación racional de las reglas desde una posición original contractualista pareciera ser de una vez y para siempre. Sus principios no serían corregibles ni impugnables. Una vez establecidos y aceptados como bases del contrato, éste tendría que cumplirse hasta la consumación de los siglos, o lo que es lo mismo, hasta la muerte de la generación de individuos ¿racionales? que lo hubieran acordado. Por esto Rawls suscribe desde su lógica procedimental el dicho "hágase justicia y perezca el mundo", cosa tan inadmisible para el consecuencialismo pragmatista como para el sentido común.

Los hombres pueden ser racionales, incluso con esos prejuicios que Rawls quiere eludir colocándolos tras el velo. Los seres humanos no podrín ser racionales (ni irracionales) en ausencia de prejuicio alguno. Toda decisión -incluida la decisión de elegir principios a partir de los que decidir lo que es justo o no- presupone algún tipo de conocimiento, por elemental que este sea. No habría impedimento lógico ni físico para que un ser humano, en libre ejercicio de su razón y autonomía, y aun considerando sus talentos y debilidades personales, así como su propia posición social, acuerde y acepte esos principios como guías que rijan las instituciones de la estructura básica de la sociedad, o, en su caso, para transformar éstas en determinado sentido. Es cierto que la estupidez humana -entendida como cortedad de miras e inmediatez en la percepción de deseos e intereses- es formidable, pero para reducirla no hace falta suponer posición original, ni velo de ignorancia, ni individuosátomos, ni perfecta racionalidad de estos. La simple exposición a los resultados de una práctica es suficiente cuando lo es- para reducir al mínimo esa estupidez y producir un ajuste inteligente en la práctica, pues de hecho así es como ha evolucionado la razón y la misma especie.

Otra conocida crítica a los principios rawlsianos consiste en que el ejercicio de la libertad posterior a una distribución intencional equitativa, dadas las radicales diferencias interindividuales, volvería a generar nuevas disparidades, haciendo entonces necesaria una nueva distribución (Nozick (1988), capítulo VII pp. 153- 227). Esto pretendería demostrar una inconsistencia lógica entre el principio de libertad y el de diferencia (justicia o fraternidad). Sin embargo, hay que señalar que tal crítica se sostendría desde una concepción muy distinta de libertad y de justicia, a saber, como ocurre con Nozick, que la libertad es la absoluta ausencia de interferencias: una libertad negativa y sólo negativa; y que la justicia es un estado de cosas definido y acabado de una vez y para siempre. Pero, aunque no demuestra inconsistencia lógica alguna entre los principios rawlsianos, y porque adopta

\footnotetext{
${ }^{34}$ Escribe, por ejemplo: "Estas consideraciones sugieren la idea de tratar la cuestión de las partes distributivas como cuestión puramente procesal. La idea intuitiva es estructurar el sistema social de modo tal que, sea cual fuere su resultado, éste sea siempre justo (1979, p. 89, realce añadido). Esto es inaceptable en filosofia por ser imposible en la práctica. Lo que puede llamarse el síntoma claro de la persecución de la certeza en Rawls es su idea de "geometría moral", en clara deuda con Spinoza. 


\section{Quaestio Iuris}

una visión de la justicia como algo acabado y perfecto, esta crítica de Nozick permite destacar, por contraste, el carácter conjetural de la justicia entendida desde y a través del pragmatismo: si los resultados de una distribución inicial (una práctica) generan otras inequidades, o una disminución de la libertad que sea inadmisible, entonces esas irritaciones tendrán que ser atendidas corrigiendo de nuevo la distribución que les dio origen. Es claro que la eternidad procedimental de los principios rawlsianos impide esta salida.

Si bien más tarde Nozick (1993) toma distancia respecto al concepto de racionalidad que asumió en Anarquía, estado y utopía ${ }^{35}$, los argumentos que en esta obra esgrime surgen de una concepción instrumental de la razón como un ejercicio de individuos-átomos. Esto permite decir que si ambos difieren en sus concepciones de justicia y libertad lo hacen por estar de acuerdo en lo fundamental, a saber, el concepto de razón pura y a priori.

Su crítica a Theory of Justice parte de distinguir entre teorías pautadas y no pautadas ${ }^{36}$. Según su apreciación, la de Rawls pertenece a la primera clase, en particular por la pauta de distribución explícita en el principio de diferencia, es decir, por establecer que una eventual distribución desigual debe favorecer a los peor situados. La teoría de Nozick pertenecería a la clase de teorías no pautadas, aquellas que, aún rigiéndose por algún principio -como los lockeanos de propiedad y apropiación en el caso de su propia teoría-, los resultados a que su aplicación conduzca no responderían ante ningún principio, excepto a la máxima de la libertad propia de laissez faire. Tal perspectiva resulta inmune (y se supone a sí misma impune) ante cualesquiera que sean los resultados de la elección libre irrestricta. La máxima con que resume su postura es 'De cada quien como escoja, a cada quien como es escogido' (p. 163, subrayado original). Según esto, la libertad negativa no sería corregible, y habría que mantenerse en ella, con ella y a través de ella sin importar los resultados a que conduzca. Nozick signaría, en imagen especular con Rawls, el dicho 'hágase la libertad y perezca el mundo'. Por esto, una manera de tener una visión más clara de esta libertad 'anarquista' es contraponerla no al Estado -puesto que Nozick no plantea su eliminación-, sino a la idea, prudente a mi parecer, de atarse a sí mismo (Elster, 1989) de sujetarse a normas que se forjen atendiendo a los resultados, pasados y previsibles, de una determinada práctica. Por contra, la idea de

\footnotetext{
${ }^{35}$ Son significativos de tal toma de distancia párrafos como los siguientes: "No sólo nuestra racionalidad y nuestros principios son parciales, diseñados como están para funcionar de consuno con cosas externas; nosotros, los seres humanos, somos criaturas parciales, no enteramente autónomas. Somos partes del mundo, estamos diseñados para trabajar en equipo con otras partes y otros hechos, dependemos de ellos (...) El enfoque evolucionario de la racionalidad y de sus limitaciones liga con un tema de los escritos de Ludwig Wittgenstein, John Dewey, Martin Heidegger y Michael Polanyi, [yo incluiría a Neurath y a Duhem] quienes, por distintas razones, entendieron también que la racionalidad estaba incrustada en un contexto y desempeñaba un papel como uno entre otros componentes, en vez de como un podio externo y autosuficiente desde el que juzgarlo todo" (p. 170). Al final de La naturaleza de la racionalidad (capítulo V) reconsidera y critica la racionalidad instrumental que había suscrito en Anarquía, estado y utopía.

${ }^{36}$ Hay diversas clasificaciones de las teorías filosóficas de la justicia. Además de esta de Nozick cabe destacar la muy influyente de Barry (1995), quien distingue entre teorías de la justicia como ventaja mutua y como imparcialidad. Desde luego, cada clasificación se explica por motivos particulares distintos.
} 


\section{Quaestio Iuris}

Nozick es "liberar" a Ulises de sus ataduras aunque sea devorado por las sirenas. Más que anarquista, la suya parecería ser la propuesta de una libertad incontinente e incontenible.

Nozick, al igual que Rawls, parte de forma implícita, aunque muy clara, del supuesto de un individuo autónomo preexistente al establecimiento de los principios de justicia y a cualquier contrato. La razón de tal ente autónomo (autónomo en un sentido que Nozick afirma ser kantiano), por tanto, sería individual en el sentido de ser a priori, es decir, independiente de la socialización de ese individuo. En éste radicaría no sólo la razón y la autonomía ${ }^{37}$ sino el derecho a la libertad y a la propiedad. En esto Nozick asume el individualismo ontológico y el metodológico, y la consecuencia lógica es contraponer la justicia (que implica una distribución y una intervención de un estado más que mínimo) a la libertad negativa entendida como la mera ausencia de interferencias al individuo. Para el Nozick de Anarquía... los hombres no sólo nacen libres y desiguales, sino además autónomos, racionales y ya en posesión de derechos.

La polémica entre el comunitarismo y el liberalismo y, dentro de este último, entre un liberalismo social como el de Rawls y un liberalismo anarquista como el de Nozick, suele ser vista como un enfrentamiento entre los métodos para perseguir y alcanzar una sociedad mejor ordenada, en su sentido de más justa. Tales métodos enfrentados pueden, a su vez, identificarse en dos sistemas técnicos, a saber, el Estado y el mercado. Por supuesto, las opiniones divergentes entre los partidarios de uno y otro mecanismo se basan, a su vez, en conceptos distintos de justicia y libertad, aunque suelan coincidir en un concepto de razón a priori y de una racionalidad maximizadora.

Es en este escenario que el pragmatismo aparece como una filosofía sugerente y sana para superar disolviéndolas- esas divergencias. La estrategia pragmatista parte, por supuesto, de un concepto naturalista de razón, entendiéndola como el producto de la evolución del hombre y su medio ambiente físico y cultural, y viendo en ella una capacidad moldeada evolutivamente por los resultados de su uso en la supervivencia y la bienvivencia. Considerada la contingencia del mundo, la racionalidad (como característica eventual) de una práctica ha de evaluarse en su contexto, por sus resultados $\Varangle$, sobre todo, por la capacidad del organismo (individual o colectivo) para amoldar o ajustar esa práctica según esos resultados.

\footnotetext{
${ }^{37}$ En el caso de Rawls -y por su liberalismo social-, esta misma idea de racionalidad resulta más inquietante. Pese a que de manera clara utiliza el concepto canónico de racionalidad algorítmica para producir sus principios de justicia, no tiene ni ve obstáculos al adscribir ese concepto a autores como Sen, Simon y Davidson (1979, p. 141), quienes en mi opinión sostienen posturas respecto a la racionalidad contrapuestas a la utilizada por él. Más aún, al hablar de racionalidad deliberativa, y cuando el lector espera un desarrollo en el sentido de Habermas o Elster, termina refiriéndose a una deliberación interna llevada a cabo de manera cartesiana por el individuo-átomo preexistente a toda experiencia (1979, p. 377 y ss.). Hay que decir que en Liberalismo político Rawls naturalizará, por decirlo de algún modo, su Teoría de la justicia, en particular mediante la idea del consenso traslapado -que parece su manera de distinguir entre lo público y lo privado (1995, pp. 137-170)-, y tomará una idea de razón como intercambio de razones que tiende a identificarse con la habermasiana acción comunicativa, y la deweyana necesidad del público por superar su eclipse mediante el método de la inteligencia operante (pp. 204-240). Habría entonces dos Rawls, a cuyo estudio no podemos entrar aquí.
} 
Por otro lado, si, como creo, tanto las debilidades del método de Rawls como lo descaminado en las críticas de Nozick, derivan en última instancia de un implícito dualismo individuo-sociedad ${ }^{38}$, entonces el pragmatismo permite una salida a tales problemas, disolviendo tanto la controversia comunitarismo-liberalismo, como la presunta contradicción entre libertad y justicia; y sobre todo produciendo una caracterización suficiente y adecuada del interés público posible y deseable, a saber, la justicia ұ la libertad.

La posición general pragmatista sobre el asunto diría a grandes rasgos lo siguiente. Si la justicia consiste en dar a cada quien lo que le sea debido en condiciones de una vida gregaria y cooperativa entre individuos diferentes, entonces para operarla es necesario:

1. alcanzar principios racionales (reglas intersubjetivamente acordadas) que guíen esa distribución, y

2. construir las instituciones (la rawlsiana estructura básica de la sociedad) capaces de ejecutarla con legitimidad. Esto coincide con el problema técnico y político de construir o reconstruir un Estado, es decir, puede y debe ser visto hoy como el problema de acordar un nuevo contrato social.

El punto central de la filosofía política pragmatista es la simple distinción entre lo público y lo privado, distinción que no implica separar individuo y sociedad. De la ontología relacional se sigue que la razón es un instrumento de supervivencia del individuo y de la especie; y, por tanto, que dada la imposibilidad de concebir un individuo al margen de su socialización, la razón se adquiere y se ejerce (cuando lo hace) en esa socialización.

Hacer, impartir o ejercer la justicia es entonces un asunto estricto de orden público y político, es decir, tiene como objeto de cuidado y corrección los impactos públicos del conjunto de transacciones que llevan a cabo los individuos que conforman una sociedad, asunto que ha de ser resuelto apelando a esa capacidad biocultural que es la razón. Por tanto, si el desarrollo y ejercicio de ésta es social, intersubjetivo, entonces lo que sea justo o injusto se determinará de manera convencional en el curso de esa razonabilidad. Los principios, criterios o reglas de la justicia, podrían muy bien por ello ser los mencionados por Rawls, aunque acordados por la razón natural de que disponemos, y no derivados desde una hipotética situación original, ni a partir de una “Razón” que nos resulta ajena.

La presunta contradicción entre libertad y justicia queda superada al considerar que la libertad del individuo no precede a la existencia del grupo y, por tanto, a la cooperación, o altruismo recíproco (Trivers, 1971). La libertad no sería entendida como mera libertad negativa, sino más bien, como la conjunción de ésta con la libertad positiva $\nsucceq$ la aceptabilidad racional social de las acciones que ambas permitan realizar a individuos y grupos cooperativos. En otras palabras, libertad es un poder hacer aceptable o legítimo, y es obvio que la simple libertad negativa no produce justicia (legitimidad), tal y como los resultados generales de los mercados y de los estados "libres" permiten atestiguar.

\footnotetext{
${ }^{38}$ En Rawls ese dualismo afecta al método, y en Nozick se refleja en sus conceptos de racionalidad y libertad. vol. 08, no. 04, Número Especial. Rio de Janeiro, 2015.pp. 2532-2555
} 
Justicia y libertad son condiciones prácticas del bien individual, y no un imperativo definido al margen de la experiencia transaccional. Libertad y justicia no pueden, luego, entenderse como estados reales o hipotéticos que puedan producirse de una vez y para siempre, sino que, como la verdad o la democracia, tienen que estar siendo (re)construidos a lo largo de esa práctica. Son características que pueden adquirir los procesos de la práctica, y no estados definidos o permanentes del mundo o de la sociedad. Libertad y justicia son eventuales rasgos de la experiencia transaccional humana, y no estados inmutables de La Razón o el mundo.

Las dos preguntas implícitas en la discusión, a saber, si pueden las reglas del juego establecerse antes de jugarlo, y si debería no existir regla alguna del juego, que Rawls (1979) y Nozick (1988), respectivamente, responden de manera afirmativa, tendrían que responderse desde la filosofía política pragmatista en negativa. Perelman parece compartir la posición de que las reglas no pueden establecerse a priori ni con independencia de los resultados del juego práctico, y, aunque sí debe haber reglas que lo guíen, estas son siempre corregibles según la aceptabilidad racional de sus resultados. El pragmatismo en general, y la filosofía política de la técnica en particular, permanecen en el terreno de intersección de lo física y lógicamente posible y lo éticamente deseable; donde ambas cosas, es decir, tanto el conocimiento de las leyes de la naturaleza (la epistemología) como las leyes y valoraciones humanas (la axiología) se encuentran expuestas a revisión y a eventual corrección por los resultados experimentales a que conduzcan. Como esa intersección de lo posible ұ lo deseable varía con el desenvolvimiento y evolución de la técnica misma, la racionalidad consistirá en el permanente ajuste de la práctica, en hacerla proporcionada, justa, es decir, caracterizada por cierto orden o ratio. Este orden justo tiene un objetivo: evitar la violencia, tanto la proveniente en forma de otros hombres, como la generada a través de la estructura básica de la sociedad.

La justicia como equidad, entonces, no sería la consecución de una fórmula a priori -como pretende el primer Rawls. Tampoco la libertad es la ausencia de reglas, ni puede producir la justicia, como cierto Nozick querría ${ }^{39}$.

\section{CONCLUSIONES}

Ajustar la práctica, poner cada cosa en su lugar, dar a cada quien lo que merece (sea un salario mayor, un premio, la propiedad de ciertos bienes, la horca, la cicuta, el destierro o nada) será justo si los resultados a que conduzca el suministrarle eso son aceptables por y para la comunidad que al respecto juzga y asigna eso que alguien se merece. En otras palabras, la justicia, siempre correctiva como acción en algún sentido fundamental, es a

\footnotetext{
${ }^{39}$ Los matices primer y cierto son necesarios porque se toman aquí en consideración las obras fundamentales de estos autores (1979 [1971] y 1988 [1974], respectivamente). Aunque su pensamiento y postura política cambió, ese cambio no puede aquí ser analizado.
} 


\section{Quaestio Iuris}

su vez corregible. La justicia, vista como proceso correcto, en el sentido de corregido, proporcionado (rational) del mundo de las transacciones intencionales humanas, es un objetivo práctico permanente de la técnica asociada al sistema político, al Estado.

Las nociones de justicia y libertad adquieren su significado más claro al considerarse en relación a un concepto mayor de lo político. Tal concepto mayor es el de técnica: pensar el sistema político qua sistema técnico permite dar a justicia y libertad un significado concreto como objetivos y fines de la organización política del público. Libertad y justicia serían intereses y valores compartidos por los ciudadanos -con independencia del contenido que hayan de dar a su práctica vital (su concepción particular del bien)-, porque son las condiciones de posibilidad y los medios que les permiten identificar, perseguir y alcanzar cualquier fin o bien específico. La sociedad justa y libre es el medio de alcanzar cualquier fin individual valioso: sin un mínimo de justicia y libertad, la identificación misma de los fines se hace imposible. La justicia, esa equidad, esa proporcionalidad, tanto en el trato entre los seres humanos como en las consecuencias de su práctica, esa ratio ya mencionada, es el medio fundamental de la libertad, donde medio es usado aquí tanto en su acepción de instrumento como en la de condición contextual o ambiental.

Una regla práctica es un instrumento y, en este caso, un instrumento político, puesto que tiene que ver con la justicia. Este instrumento es el Derecho que, desde luego, es una construcción humana intencional. Como expresión de los derechos y deberes entre los hombres, la normatividad jurídica es un instrumento técnico de la convivencia humana al que cabe evaluar por sus resultados. Como instrumento básico de la justicia tendría que aplicarse en los casos en que aparezca una desproporción, una inequidad, sea que ocurra en las diversas transacciones individuales, o en la distribución de valores entre los individuos que constituyen un público. Cuando esa asignación es injusta, cuando es desproporcionada o inequitativa, el instrumento jurídico es el que puede y debe corregirla y, para ello, la norma jurídica ha de cumplir con ciertas características, tales como las características que ha de poseer un desarmador para apretar o aflojar un tornillo. Esto lleva a inquirir entonces por los fines de su diseñador, constructor y operador. Si el diseñador y constructor es el legislador, entonces se aclara que en el caso de la justicia (asunto central de la política) enfrentamos el problema de la representación, la participación democrática y la eficiencia legislativa de las que depende la legitimidad de la ley, la aceptabilidad racional de esa regla que enuncia la justicia ${ }^{40}$ y sus resultados.

La razón, entendida como evaluación crítica, se manifiesta de forma relevante sólo si va acompañada del poder político. De ahí la pertinencia filosófica y la necesidad práctica de preguntar por los ciudadanos capaces de ejercitar la razón, participar en la organización del Estado y del gobierno, en su operación, en su vigilancia y en su

\footnotetext{
${ }^{40}$ Para un análisis crítico detallado del derecho como discurso del poder y la legitimación véase Giménez (1983), en particular el capítulo III, pp. 65-94.
} 


\title{
Quaestio Iuris
}

control. El asunto de la producción técnica de la justicia, al cruzar por el problema de la construcción de la democracia como modus operandi de la política, se conecta con el tema de la ciudadanía, y que se refiere a las características o atributos de los individuos que habrían de participar en esa organización, operación, vigilancia, evaluación y control del sistema político qua sistema técnico.

\section{JUSTICE AND TECHNIQUE: PRAGMATIC POINT OF VIEW}

\begin{abstract}
This essay stands for a technical conception of politics. As a logical consequence propounds a certain concept of justice which allows distinguishing it as the main objective of that technical system we know as the State or political system. From the John Dewey's instrumentalist and pragmatist naturalism (experimentalism), citizen's freedom here is understood as the statecraft's end coupled to that technical objective named justice. Political system is conceived as the basic technical system, and the Law as its central instrument. Finally I attempt to locate the keynotes of a naturalistic political philosophy by contrasting it with Rawls's and Nozick's views.
\end{abstract}

Keywords: technic, justice, freedom, State, pragmatism, instrumentalism.

\section{REFERENCIAS}

ALEXY, R. (2003). Justicia como corrección, en Doxa, no. 26, pp. 161-173, Universidad de Alicante.

ARISTÓTELES.Ética a Nicómaco, Gredos, Madrid.

BARRY, Brian (1995). Teorías de la justicia, Gedisa, Barcelona.

(1997) La justicia como imparcialidad, Paidós, Barcelona.

BUNGE, M. (2000). El derecho como técnica social de control y reforma, Isonomía, no 13, pp. 121-137, ITAM, México.

CAMPS, V. (1996). “Introducción” a Rawls, J:: Sobre las libertades, Paidós, Barcelona.

DEL CASTILLO, Ramón (2003). “Introducción”, en Dewey,J.: Viejo y nuevo individualismo, Paidós, Barcelona.

DEWEY, John (1935) Liberalism and Social Action, Putnam's Sons, New York.

(2003) Viejo y nuevo individualismo, Paidós, Barcelona.

(2004) La opinión pública y sus problemas, Morata, Madrid.

(2012) Teoría de la valoración, Uniminuto, Bogotá.

EASTON, D. (1981) The Political System Besieged by the State, en Political Theory, Vol. 9, No. 3, pp. 303-325, Sage Publications. 
ELSTER, J. (1989). Ulises y las sirenas. Estudios sobre racionalidad e irracionalidad, FCE, México.

FISHER, J. (2010). El hombre y la técnica: hacia una filosofía política de la ciencia y la tecnología, UNAM, México.

GEHLEN, A. (1993). Antropología filosófica, Paidós, Barcelona,.

GIMÉNEZ, G. (1983). Poder, estado y discurso, Instituto de Investigaciones Jurídicas, UNAM, México.

HOBBES, Thomas (1998). Leviatán, FCE, México.

KELSEN, H. (1991). ¿Qué es la justicia?, Fontamara, México.

NOZICK, Robert (1988). Anarquía, estado y utopía, FCE, México.

(1995). La naturaleza de la racionalidad, Paidós, Barcelona.

ORTEGA y Gasset, J. (2005). Meditación de la técnica, en Obras Completas, 6a Edición, T. V. pp. 317-378, Revista de Occidente, Madrid.

PASCAL, B. (1993). Pensamientos, Altaya, Barcelona.

PERELMAN, Ch. (1964). De la Justicia, Centro de Estudios Filosóficos, UNAM, México.

PLATÓN (2008). República, Gredos, Madrid.

QUINTANILLA, M. A. (2005). Tecnología: un enfoque filosófico, y otros ensayos de filosofía de la tecnología, FCE, México.

RAWLS, John (1979) Teoría de la justicia, FCE, México.

(1995) Liberalismo político, FCE, México

(1996) Sobre las libertades, Paidós, Barcelona.

(2001) La justicia como equidad. Una reformulación, Paidós, Barcelona.

SCANLON, Thomas (1982). Contractualism and Utilitarianism, en Williams and Sen (Eds.) Untilitarianism and Beyond, Maison des Science de l'Homme and Cambridge University Press, pp, 103-128, Cambridge, U. K.

SEN, Amartya (2002 a). Capacidad y bienestar, en Nussbaum y Sen (Eds.) La calidad de vida, FCE, México. (2002 b) Rationality and Freedom, Harvard University Press, Cambridge, Ma.

TRIVERS, R. L. (1971). The Evolution of Reciprocal Altruism, en Quarterly Review of Biology, n 46, pp. 35-57, University of Chicago Press, Chicago.

WALZER, Michael (1993). Las esferas de la justicia. Una defensa del pluralismo y la igualdad, FCE, México.

Trabalho enviado em 14 de setembro de 2015.

Aceito em 07 de outubro de 2015. 